\title{
Insights on Impact of Business Development Services on Growth of Women Owned Enterprises in Tanzania
}

\author{
Nyamagere G. Sospeter ${ }^{1} \&$ Mariam I. Nchimbi ${ }^{2}$ \\ ${ }^{1}$ Ardhi University, Dar es Salaam, Tanzania \\ ${ }^{2}$ University of Dar es Salaam Business School, Dar es Salaam, Tanzania \\ Correspondence: Nyamagere G. Sospeter, Lecturer at Ardhi University, Dar es Salaam, Tanzania.
}

Received: January 15, 2018

Accepted: January 30, 2018

Online Published: February 21, 2018

doi:10.5430/jms.v9n1p82

URL: https://doi.org/10.5430/jms.v9n1p82

\begin{abstract}
This paper presents findings of the study that aimed at assessing the impact of business service providers (BDS) on growth of women owned MSMEs in Tanzania. Based on interviews conducted to five BDS providers and women owned micro and small enterprises (MSMEs) it was revealed that most women entrepreneurs were not aware of the existence of BDS providers and their services. For those who had used BDS, they were generally satisfied with their benefits and they continue using the services. Furthermore, the findings show that BDS assisted entrepreneurs in formalizing their businesses, increased business management and technology capacity, market coverage and contributed to business growth.

Findings calls for the government, BDS providers and other key stakeholders to raise the level of awareness to women entrepreneurs on the availability and importance of using of BDSs. Government and donor community should advocate for business environment reforms that lowers the barriers to BDS providers for them to operate effectively and provide affordable services. BDS providers should focus on demand driven services in a more holistic and participatory way than they are currently doing in order to improve the quality, sustainability and development of the women owned MSMEs.
\end{abstract}

Keywords: women, entrepreneurship, business development services

\section{Introduction}

Despite women's involvement in business activities and their contribution to wealth creation and employment, their growth potential has not been fully realized because of the systemic challenges that face them (Lincoln, 2010; Nchimbi and Chijoriga, 2009; Rosa, 2013; Sospeter, 2017). Apart from the challenges inherent in the SME sector, women entrepreneurs face additional problems associated with being women. Women are marginalized due to social structures and cultural systems that not only reinforce the continued subordination and marginalization of women but have major impact on their involvement in business and perception of success (Gupta, Turban, Wasti, \& Sikdar, 2012; Nchimbi and Chijoriga, 2009; Welter, 2011). Partly as a result of this, women are limited to further educational, technical skills, employment opportunities, general exposure, lack of free time, most women entrepreneurs in the sector have limited formal and business education and work experience which are very important for business start-ups and development. Women in MSMEs sector also lack property rights and have limited ability to generate savings. As a result they lack collateral and savings necessary for accessing business finances hence decide to engage in informal, micro level businesses mostly in the low growth industries where they face stiff competition and limited growth.

The need for business development services (BDS) emanates from the increased level of competition resulting from the ongoing economic liberalization and globalization of world trade. In order to keep their positions in the market and compete, businesses, including those owned by women, need to learn to become more innovative and agile. This calls for BDS and policies to be supportive to the SME sector in general and to women entrepreneurs in particular. The need for BDS to women entrepreneurs is also seen from the fact that although the proportion of women entrepreneurs in business is higher (54\%) compared to male entrepreneurs who own 46\% of MSMEs (MIT, 2012; Sospeter, 2017), their business ventures have a lower propensity to grow and be successful than those owned by male (Welter, 2011; GEM, 2012; Nchimbi and Chijoriga, 2009 and URT, 2012). Compared to men, women are also faced 
with lack of human and financial resources as well as inadequate BDS which are vital to running successful business (Hasson, 2009; Lincoln, 2010). Therefore, women entrepreneurs are somewhat disadvantaged when it comes to receiving BDS such as financial, business management, technical skills to their business (GEM, 2012, Hakala, 2008).

This study was motivated by the dearth of research on the impact of BDS on promotion of women entrepreneurship. While Business Development Services (BDS) has been studied in other countries, the majority of these studies have largely focused on the roles, building sustainability, profile, characteristics and their motives (Alwaryd, 2009; Lingsey, 2012; Rosenbusch, Rauch, Parker \& Unger, 2009). Furthermore, the majority of these studies have focused on developed countries with a paucity of studies in developing countries (Lincoln, 2010; Hakala, 2008). The impact of business development services (BDS) on the growth of women businesses has not been studied as fully as those of their male counterparts who have to a great extent benefited from these services. Therefore, there is a growing need for specific studies on the impact of BDS in promotion of women entrepreneurship within Sub Saharan Africa (SSA) including Tanzania. This study therefore aimed at filling this gap by providing insights about the impact of BDS in promoting growth of women owned MSMEs. It specifically presents the motives and types of BDS in the development of women MSMEs, assessment of women's awareness of the BDS and benefits/impacts arising from their use and finally the extent to which BDS assist women MSMEs to formalize and grow their businesses.

The motivation to focus on women entrepreneurship in the MSE sector was threefold: First is the increasing number of women active in the MSE sector, in both developed and developing countries. Women owned enterprises in Tanzania constitutes 54\% of all enterprises in the MSME sector (MIT 2012); Secondly is the important role played by these enterprises in social and economic empowerment and hence in poverty alleviation and welfare improvement of women entrepreneurs and their families. It is believed that self-employment and entrepreneurship increase women's self-esteem and confidence, thus leading to greater control over their lives in social and economic spheres (Sospeter, Nchimbi, Rwelamila \& Masoud, 2014). Lastly, is the fact that women are considered to be better suited to handle money and to make sure that the income through their entrepreneurial endeavors goes to the best use (GEM 2010; ILO 2007). The fact that women have the entrepreneurial potential as men do to contribute to wealth creation and employment through their own businesses (Lincolin, 2010; Nchimbi \& Chijoriga, 2009; Rosa, 2013), makes supporting their businesses through BDS more vital to their family wellbeing and hence poverty alleviation.

The paper is organized in five sections: the next section reviews the literature followed by the methodology before presentation and discussions of findings. The last section presents conclusions and limitations.

\section{Literature Review}

\subsection{Women in SME Sector in Tanzania}

Women's entry into businesses is closely associated with the economic crisis of the late 1970s and 1980s and the subsequent Structural Adjustment Programmes (SAPs) of the 1980s (Gupta et al., 2012; Nchimbi and Chijoriga, 2009; Lingsey, 2012). The SAPs intended to address the economic recession of the mid-1970s. SAPs required the government to cut down spending and to privatize state-owned enterprises, leading to massive retrenchment of public servants, a sharp decrease in incomes and significant unemployment problems (Nchimbi, 2003; Sospeter et al., 2014). As a result, self-employment activities in the Micro, Small and Medium Enterprises (MSME) sector became the immediate solution for employment and income generation. Women had to engage in business so as to create self-employment as well as to supplement their income for their families. Of recent, women have been increasingly involved in the sector either as employees or as operators. The 2010 Tanzania's MSME survey revealed that, 54.3\% of businesses are owned by women (URT, 2012; Sospeter, 2017). As compared to men, majority of women business ventures are found to be micro employing not more than 4 employees and in low growth areas, thus they have a lower propensity than men-owned to grow and be successful. Therefore, any positive or negative developments in the sector will have a direct corresponding effect on the plight and livelihoods of women.

The available literature shows that the majority of women entrepreneurs prefer to establish a number of multiple micro enterprises rather than to develop a few activities for growing into small or medium-scale enterprises (Sospeter, 2016; Lincolin 2010; Welter, 2011). In addition, women entrepreneurs are more likely to have multiple ownerships compared to male entrepreneurs. Even when they are engaged in one industry, such as food processing, they tend to deal with multiple products, some of which are unrelated. For example, women food processors in the SME sector can process peanut butter, honey, pickles, juices, wine, maize flour and sausages simultaneously. Such a wide mix of activities not only impact the level of growth, but makes it hard for them to qualify for the stringent licensing requirements for food processing for any of the products (Sospeter et al., 2014; UDEC, 2002).Ultimately, their multiple dealings with unrelated products or services are reflected on the motives as well social structures and cultural systems. 


\subsection{Constraints Faced by Women in the MSE Sector}

Women in the MSE sector face a number of serious obstacles. Among these are: gender-insensitivity in macroeconomic policies, complex tax policies and compliance procedures, gender-based inequalities in employment policies and regulations, complex business registration and licensing procedures for the smallest micro-enterprises (where the majority of women are found), lack of cultural acceptance of the role of women as entrepreneurs, limited access to appropriate business premises, limited access to BDS, lack of collateral due to property ownership practices, lack of access to term loans and sufficient working capital to meet their needs (the gap between the micro-finance ceiling and the minimum loan requirements of banks), and the limited organizational and management capacity among women's advocacy groups (UDEC, 2002; URT, 2012). SMEs also have a lower demand for BDS such as training, counseling, advising and consultancy, due to cost considerations and lack of knowledge about the benefits of external services in improving competitiveness (URT, 2012; Sospeter, 2016). In addition, women face a number of gender-related problems: lack of property rights over assets, lack of confidence in women by bank officers, gender roles which limit free times for accessing markets, discouragement from men when starting or formalizing businesses, social restrictions regarding networking with men in business, and suppliers sometimes insist that they deal with the entrepreneur's husband when decisions are being made (ILO, 2003; Sospeter, 2016). On the other hand, the factors that enable women to effectively manage their enterprises are skills, knowledge and expertise, talents and abilities in business, and a compelling desire to achieve a goal by doing something positive and constructive (Kapp and Hunter, 2008; Gupta et al., 2012). These skills are largely lacking in majority of women entrepreneurs. This implies that efforts through BDS to develop these attributes need to be pursued at all levels of the society in order to bring about socioeconomic transformation through female entrepreneurship (Kapp and Hunter, 2008; Gupta et al., 2012).

\subsection{An Overview of Business Development Services}

The term Business Development Services (BDS) refers to a wide range of non- financial services provided by public and private suppliers (BDS providers) to entrepreneurs to help them operate efficiently and grow their business with the broader purpose of contributing to economic growth, employment generation and poverty alleviation (URT, 2012; Rosa 2013). There are three types of BDS namely; generic- these services are available and applied in large numbers. Services like Tax consultants that are transactional in nature fall under this category. Embedded-such services come bundled with some products or services. Services like maintenance of machines, technical services, micro financing or incubation services that are preceded by training, for which the user does not have to pay anything extra. Strategic- this category includes services that are strategic in nature. Most of SMEs are supported by these services. Services include assistance with market access; input supply; technology and product development; training and technical assistance; infrastructure; policy/advocacy and dialogues well as alternative financing mechanisms (GEM, 2012; Gupta et al., 2012). The services both operational and strategic are critical to the survival and growth of SMEs (GEM, 2012). These services are designed to serve individual businesses as opposed to the larger business community.

The types of services in a functioning BDS system are determined by the demand articulated on the part of the businesses (Fakhri, Ghanimat, Koopahi \& Behnie., 2012). BDS are offered by either formal or informal providers who are individuals, private/public enterprises, institutions, non-governmental organizations (NGOs) and government agencies specializing in creating and delivering BDS to SMEs (Fakhri et al., 2012; Olomi, 2009). Studies show that, apart from the formal BDS offered to clients, there are many examples of BDS being provided through informal exchanges between clients. For example, although a woman attends her weekly solidarity-group meeting at a certain Micro Finance Institution with the main purpose of repaying her loan, her interaction with her fellow group members, provides her with many other sources of BDS. She often acquires, for example, improved input services when her group decides to join together to buy inputs in bulk to get better prices from the wholesaler. She also acquires business training when her group leader teaches her how to use a calculator to calculate her profit margins. Similarly, when her loan officer identifies a business opportunity with a new retailer, the woman is essentially acquiring a business linkage service (Alwaryd, 2009).

In order to create a demand driven market approach, the following should be considered as the characteristics for BDS market delivery and development; Focus on market, the providers should focus on what is needed in the market and not what they think they can offer. For example, to offer services that address women SMEs specific issues. Services should meet the requirements of the customers in terms of kind of service offered, quality, capacity to pay for the service and way of delivery. View clients as customers, BDS providers should view their clients as customers and not as needy people who have no alternative. According to Olomi (2009), he suggests that, poor micro 
entrepreneurs demand different services compared to enterprises with more sophisticated company structures. Services delivery models and mode of payment also differ. Services have to be more tangible and benefits have to become visible quickly. He further noted that, experts have observed that among micro entrepreneurs (where a large percent of women are found) demand for basic services such as information and communication, market linkage and input supply which are seen as stronger than it is for strategic as well as business management training. All in all, BDS are important as they can assist women entrepreneurs to run their business more effectively and if appropriately applied, can create access to finance and act as an alternative form of collateral in circumstances where tangible collaterals may be an impediment to meeting traditional security requirements.

\section{Methodology}

The case study research method has been used in this research. The approach was considered useful as it permitted the investigation of a contemporary phenomenon in its real-life context to take place and thereby aid for understanding the roles BDS play to assist women when starting, formalizing and developing business ventures in their real life. The case study approach provided the possibility of gaining insights into the experiences, their profiles and characteristics of BDS providers (Yin, 1994; 2009; Stake, 2006). Eight cases (8) of women entrepreneurs and 5 BDS providers were conducted. The use of multiple cases allowed the key themes from recurring concepts, relationships and explanations to be tested in several different situations.

Information about women entrepreneurs was obtained from Tanzania Women Chamber of Commerce (TWCC) and Small Industries Development Organization (SIDO) data base to establish the number of women and profile of the targeted BDS firms before embarking on the case study. Dar es Salaam and Mwanza were chosen firstly to serve as a standard because of the availability of many women entrepreneurs. Secondly, there are more business opportunities than in other towns. Thirdly, it was convenient and cost effective to do repeated interviews in Dar es Salaam and Mwanza. This is to say, it was possible for the researcher to follow up through repeated social interactions with women entrepreneurs which in turn facilitated direct observation. The following criteria were used to select BDS Providers

i. The organization should be registered with at least more than $31 / 2$ years' experience as per (GEM, 2012; ILO, 2003) suggestion

ii. The organization should have provided services to women MSMEs

iii. The organization should have served more than 30 women MSMEs from different sectors e.g women traditional industries (WTIs) e.g food, textile and beauty sector and male dominated industries (MDIs) e.g construction or manufacturing.

Criteria set to select women entrepreneurs were:

i. The business should be owned by a woman or if jointly owned then the woman must have majority shareholding.

ii. The woman owner makes critical business decisions

iii. The business should have received BDS for at least one year effectively

Thus a sample of 11 respondents, 5 being BDS providers and 8 being women entrepreneurs were used for case study. BDS Providers were asked on what and how do they provide services to WOEs while WOEs were asked the type and how the services provided to them impacted their businesses. Interested respondents were selected and interviewed. Women MSMEs who expressed their perceptions, experiences and opinions on the experiences of receiving BDS were purposively selected. The cases chosen appeared to qualify based on the initial interviews and the criteria set. The interviews were conducted first with Women and then to BDS Providers before embarking to key informants. The interviews were extended to outside the firm's key informants, including customers who had received services from MSMEs or employers who had worked with them. It was necessary to involve them in the study in order to get different views and gather detailed information. In addition, the use of multiple sources of evidence in case studies allowed the researcher to address a broad range of historical and behavioural issues exhibited by both women and their BDS providers. Data was analyzed by organizing the data into categories on the basis of the themes and concepts, after which the relationship between the concepts was then analyzed and finally linked in a sequence (Creswell, 2009; Neumann, 2006). The themes from the interviews were used to form common patterns to answer the research question.

\section{Findings and Discussions}

This section presents the analysis and discussion of the findings. It explores the information from the cases selected; 
5 BDS providers and 8 women MSMEs that address the research questions. The presentation is done according to emerging themes and section has been divided into four sub-sections:

\subsection{The Roles of BDS to MSMEs}

In discussing the role of BDS in regard to women MSMEs data were collected by interviewing BDS providers through unstructured interview guide and questionnaire designed for MSMEs survey. During analysis a number of variables were identified as discussed below:

\subsection{The Motive for Establishment of BDS}

The general view of contacted BDS providers on motives for establishing and developing BDS were: to provide BDS to clients as per demand, to improve the quality and sustainability of MSMEs and to increase their growth levels. Another motive for most of them was to use the acquired skills and experience in their field or profession. This was followed by the need to earn their living as well as to provide BDS and financial services on demand to SMEs. Lastly their motive was to develop the entrepreneurial skills and capacity of SMEs. However, the cases revealed that there has been great positive impact on the businesses of women MSMEs that have received BDS. Although BDS providers are well motivated, in terms of outreach they are still limited, this is due to the limited capacity to serve a wide range of services to a widely spread clients such as women MSMEs as well as the whole market. Most BDS providers are serving urban areas only.

\subsubsection{Types of Services}

The information from BDS providers reveals various roles of their services to support business growth, especially in regard to women entrepreneurs. Apart from the role of providing demand-driven services, another role is actively promoting linkages between corporate sector and SMEs and encouraging commercial sponsorship for marketing events. Moreover, BDS help in networking with other NGOs and umbrella organizations working with SMEs to broaden the support base and enhance lobbying activities which are necessary for sustainable businesses. Most BDS providers were established in the 1990's after the economy was liberalized, whereby the private sector was given an upper hand in assuming the responsibility for economic growth in Tanzania (The National Development Vision 2025). Since that time, the main types of services provided include entrepreneurship development and training, market and marketing linkages, business management skills, technical training, technology development and transfer, advisory and consultancy services, and other services.

Findings from the cases show that only SIDO out of the 5 BDS providers under study provides business information and technology development and transfer. SIDO can afford to provide technology development and transfer, together with business information services because it is a relatively large government owned organization. Technical training and marketing services require huge capital investment and specialized expertise which can only easily be provided by government agencies and NGOs. Other BDS providers need only knowledge, skills and experience for them to provide the services like advisory and consultancy, entrepreneurship and business management skills as well as other support services. That is why all BDS providers regardless of their category, provide advisory and consultancy services. It was further revealed that most BDS providers, except SIDO, are of small size with the number of employees not exceeding 5 permanent staff (both professional and support staff), not highly networked, they have one or no branch offices at all and very few associate consultants with whom they work as a team in case there is any consulting job.

\subsubsection{Main Clients}

It has been revealed though the targeted clients for all 5 BDS providers in the cases cited are SMEs, BDS providers were found to provide their services to other groups in society. That is to say they provided services to women owned MSMEs, NGOs, religious organizations and development agencies. It was further revealed that the main clients for SIDO, PIL and BEST-AC are women owned MSMEs, as compared to the SMEs group which was the target group. According to the SIDO branch manager, the main reasons why the focus on target group has shifted is that most SMEs especially those owned by men find themselves comfortable and thus less dependable on BDS, since they have already established their markets, have better networks, better access to information, considerably more power in bargaining than to women owned MSMEs. They (BDS) have targeted more on women MSMEs in order to promote them as they have been left behind in everything for a long time.

\subsubsection{Mode of Service Delivery and Feedback}

The findings revealed that many BDS providers prefer to use a combination of methods for delivering their services to their clients. These are by the use of face-to-face interviews in the office of the BDS Providers, by using email and 
by visiting their clients in their workplaces. However, it was noticed that the method of using websites and visiting the clients is the least preferred. This is because a lot of SMEs are located in remote areas where there is no access to the internet and where there is poor infrastructure. Also the cost for connecting, operating and maintaining internet services might seem high compared to the nature of businesses to most MSMEs. Most women owned MSMEs who get those services are in urban areas, and since BDS are also found in urban areas it is easy to visit them. The means of getting feedback from the BDS recipients (MSMEs) about the quality of the services and their awareness, opinions and understanding on wide range of services, BDS utilization and opinions about a wide range of BDS services tend to be the same for all BDS providers. They also get feedback through self-observation, assessment and evaluation done by BDS providers and from the comments of the general public. Most of them get feedback from a combination of all the ways mentioned above.

Generally, BDS providers make a follow up by visiting, phoning and writing to their clients some months after delivery of the services to find out the level of satisfaction experienced by the clients and for the sake of maintaining communication between them. Others organize a forum where clients and BDS providers meet and exchange ideas in the form of conversation. The BDS providers, who provide the training in the form of seminar, workshops or in class teaching, always arrange for daily and final assessment by participants, and or even tracer studies. Lastly, clients appreciation in the form of word of mouth, e-mail, telephone or letter sent to the BDS provider also gives an indication of the satisfaction of the client with the service received. All BDS were provided as per demand. During provision of services they used the acquired skills and experience. This imply that, they did not want to incur more cost on getting specified service as it would increase the cost of service. As a result, they were limited in terms of outreach which makes them serve the urban market only.

\subsection{The Extent to Which BDS Assist Women MSMEs in Formalization}

The following sub-sections are findings from 8 women MSMEs, 3 from the food processing sector (with the names of Faraja, Feda and Fibe) for CASES 2, 3 and 4 respectively, 3 from the textile sector (with the names of Teddy, Tone and Tunu) for CASES 1, 5 and 6 respectively, and the last 2 from beauty salons (with the names of Berinda and Betty) for CASES 7 and 8 respectively. An analysis and discussion are about the contribution of BDS in the formalization of women MSMEs. The information given by the owner managers and directors from women owned MSMEs, briefly explains the impact of BDS on their business, as well as indicating the changes in various aspects of the businesses from when they were established and the current status. These aspects include legal status, bank accounts and licenses:

\subsubsection{Reasons for the Decision to Formalize}

The findings from women MSMEs revealed two reasons accounted for their decision to formalize. First, the businesses had grown to a level where it was difficult to sustain them without being constantly harassed by tax officials. Secondly, they needed to establish formal premises and procedures in order to attract more customers. All women from food processing said that it is difficult for them to sell their products to supermarkets and other related shops because they demand receipts, which they could not issue without a licence. Furaha further noted that, had she not relocated to formal business premises, she would not have been so popular for the wine, tea masala and mango pickles that she produces. As to what motivated formalization, the main reason cited by the women is profitability of the business, which gave them the confidence to commit themselves to paying rents and taxes.

It has been shown that the types of BDS received include advisory and consultancy services, business management skills and entrepreneurship development training, mobilizing linkages between MSMEs and financial institutions as well as finding markets for them. It can be observed that most MSMEs are of small size and they started informally. This supports the study done by UDEC (2002), Gupta et al (2012) and Nchimbi and Chijoriga (2009) that, women are predominantly found in informal, micro level, and low-growth sectors, where they encounter high competition while earning subsistence income. The services have helped them in that, they insist clients to register businesses in order to attract more and bigger markets. All 8 businesses 3 from food processing, 3 from textile and 2 from beauty salon are now formally operating. Furthermore, the findings revealed that, through seminars and workshops, they have gained a lot by sharing knowledge on how to overcome challenges and they also learnt how to become proactive in business rather than reactive. The type of service they received depends on the nature of the business together, with the services available from the BDS provider.

\subsubsection{Legal Status}

In terms of legal status, nothing has changed. All businesses started as sole proprietorships, except one from tailoring sector that started as a group (which is not registered as a partnership or cooperative union) and have remained so. In 
contrast, there have been significant changes in terms of the type of licenses used by the women. The proportion of women with no licenses at all has decreased from 8 out of 8 when they started business to 1 to date. A more dramatic change can be observed in the number of women who have principal licenses. This number has increased from 1 with a principal license to 7 .

\subsubsection{Opening a Bank Account}

As far as the opening of bank accounts is concerned, there are noticeable developments. While 7 out of 8 did not have any bank account for the business when they started, the current status shows that all have bank accounts. At the same time, the proportion with savings and current accounts now has increased from 2 and 1 to 8 and 6 respectively, out of the 8 . Women from food processing own current accounts too. Generally, most women entrepreneurs who participated in the case study have formalized their business activities. Of the 7 women who started informally, all have acquired formal business premises and principal licenses.

\subsection{Benefits Derived from BDS as Perceived by Women Entrepreneurs}

From the findings, it was revealed that women entrepreneurs admit the importance and benefits of BDS to their businesses. They appreciate the benefits of those services as they have brought considerable changes to their businesses, such as their products have become known to wide range of customers (marketing), they have gained confidence in their dealings, especially during running their businesses, they have been helped with networking, negotiation skills and expansion of their businesses and they have gained general knowledge about how to run a business successfully. Women can also gain decision-making experience and a greater sense of control over their lives through starting and managing a business. All these can be achieved through BDS. The impact of BDS such as advisory and consultancy services, training in business skills, technical skills, information and marketing (trade fairs, advertising, etc.) are analyzed below:

\subsubsection{Advisory and Consultancy Services}

The findings reveal that most micro enterprises prefer advisory and consultancy services, while small enterprises prefer entrepreneurial and business training, technical training. This is because, women require more support and assistance from the consultants in order to provide them with the services. Furthermore, it is easy to find these types of services in-terms of cost and time. At the micro level, women MSMEs need support in starting a business, developing saving culture and business systems. Women MSMEs indicated that, these services raise their productivity as they provide them with the advice needed to start and grow businesses. These services develop the capacity of enterprises to better plan and manage their operations and to improve their technical expertise. For effective managing an enterprise requires some managerial skills, entrepreneurial competencies and practices as well as knowledge of legal matters. All these require special knowledge and techniques that MSMEs do not have.

\subsubsection{Business Skills Development}

A modern business that operates in a globally influenced environment needs entrepreneurs, including MSMEs that are aware of the business environment and opportunities to be able to follow the development in global business and capture any opportunities in the global market. Of the 8 women entrepreneurs interviewed, those in food processing had attended business skills training and entrepreneurship courses organized by the Small Industries Development Organization (SIDO) and / or TAFOPA, their association. They explained that, the benefits for attending trainings are evident. Women are able to plan, price, keep business records, care their customers and negotiate well. These aspects are key for business growth. Regarding the women in textile and beauty services, 3 out of 4 attended such training, a two-week course organized by Poverty Africa. However, Teddy being one of the three could not afford the time to complete the training, due to commitment at home and the fact that some of her most important clients wanted their clothes to be done by her personally. Tunu and Betty have attended the training, they could not afford to complete the training because customers insist on being served by them personally, and they cannot afford to lose them. The findings revealed that entrepreneurship and business training enabled women MSMEs to understand and access business information and identify opportunities, so that they can identify areas for new investments and market trends and deal with regulatory and other challenges. This is consistent with the researchers who noted that women who attend business training will not remain the same as the training make them think and operate in an entrepreneurial way (Sospeter et al., 2014 and Rosenbusch et al., 2009).

It was further noted that, Tailors and beauty clinicians, who are growing their businesses, will continue to face serious difficulties in relation to being able to leave their businesses and attend training. Part of the problem is that the training offered to MSE operators is perceived as too basic for the relatively advanced women entrepreneurs. For example, Furaha has studied commercial subjects at secondary school and has been training other women in food 
processing. At the same time, Teddy was doing the same training to other women in tailoring at the Vocational Education and Training Authority (VETA) centre. Once Teddy tried to lease tailoring machines, but the NGO, which was leasing them, required her to attend a related course for two weeks. When she looked at the contents of the course, she found them to be too basic to be of any use to her. She thought she already knew much more than what they had to offer, and could not afford to be away from her business for two weeks and not learn anything new. She decided not to attend the course and hence was not able to lease the equipment. Furaha laments that "many organizations, which are supporting women entrepreneurs, think that all women are looking for the basics, when in fact some women have achieved a degree of development and are only constrained from developing further because of lack of appropriate and often advanced support". The findings further revealed that, in rendering their services, BDS providers are not distinguishing the category of the MSMEs in terms of commitment level, growth and education level.

\subsubsection{Technical Skills Development}

Two women engaged in food processing covered by the case study had received support in terms of technical skills from SIDO. The programme had a component of ordering and selling packaging materials and labels to women who attended the training. The women use common labels until they are able to meet the costs of ordering labels for their own businesses. In addition, they get on-site visits and advice from the trainers of the programme. Women in food processing who are members of TAFOPA have benefited too. In order to maintain some legitimacy, they print the TAFOPA logo on all their labels. Women who have gone through the programme are convesant with ways of packaging their products. Part of the problem is that the training does not teach about the designing of labels and packaging materials. Women further revealed that, the training enabled them with required skills, mindset change, awareness and knowledge of policies, rules and business environment at large.

On the other hand, BDS has assisted women entrepreneurs in many ways. For example, Teddy from tailoring has attended the training and reported that it has assisted women entrepreneurs in accessing simple machines for oil seed extraction, soap making, batik making and much more. MSMEs have benefited a lot from the technical training by gaining access to different processing machines. Sometimes, the trainings are too general. While there are no technical skills development in the beauty sector, BDS providers do assume the technical skills services of one sector to cover all women MSMEs. So far, there is no institution in Mwanza involved in technical skills development for women in beauty care, although this is one of the sectors, which many women are engaged in, especially in urban areas. They rely on foreign expertise and technical training by the cosmetics suppliers on how to use their products. That is why to some of the women engaged in the beauty care sector obtained their training by going to neighbouring countries, including Kenya. Other women entrepreneurs have gained technical knowledge by hiring salon expert from the Democratic Republic of Congo (DRC), who are accepted by most clients. However, this is only possible for women who have already established themselves sufficiently to pay the high salaries which employees from DRC or other places demand. Through employing experts, women get on the job training. The Vocational Education and Training Authority (VETA), which is the training and apprenticeship training institution for Tanzania, does not provide specific training in beauty sector, according to Berinda, who has attended training in Kenya.

\subsubsection{Trade Fairs and Advertisements}

The women entrepreneurs in food processing, as well as those in tailoring, have also benefited from various trade fairs organized by Tanzania Gatsby Trust (TGT), SIDO, Equal Opportunity for all Trust Fund (EOTF), and other local and international organizations. The information on these fairs is often communicated to them through the UNIDO-supported food processing programme, or through their sectoral associations. Women who have attended trade fairs reported that these events had been very useful in exposing them to ideas, as well as in creating awareness and increasing the sales of their products. Feda and Fibe from food processing and Tone and Tunu from textiles reported that they met most of their big customers during trade fairs. Through trade fairs, they meet other business people and learn from them. They were able to share some experiences and also learn to improve the quality of their products. However, they lamented that the fairs are always very long in duration (7-10 days) and they cost a lot in terms of subsistence, especially travelling all the way from other regions to Dar es Salaam.

Sometimes SIDO and other BDS providers used to arrange mini trade fairs in the region. It is also difficult for them, as women, to go to trade fairs for long periods, leaving behind their children, spouses and other family members. As a result, they have started using assistants to attend the trade fairs, which was the case for Teddy and Furaha during DITF 2010 year. Tone claims that "you know what, when you go there it is more than being in the fair" you talk to people, you network, you share ideas, you get new markets etc. the findings revealed that, women MSMEs benefit when they attend Trade fairs personally but not by sending assistants because assistants will only display the 
products. It may not serve the purpose of advertising their products to a public as well as linkage and networking. The Trade fair facilitated women with promoting their products through exhibitions as well as implementing mass media promotion campaigns.

\subsubsection{Marketing Services and Information}

Some of the women seem to be missing business opportunities due to lack of information. There are also few mechanisms in place for providing basic marketing information or advice to women entrepreneurs. For example, Tone packs tasty and nice sardines in Mwanza town. For three months, she used to sell them to people passing by her place of business at very low prices, just for trial. She later found her sardines being sold to people outside Mwanza at four times the price she was getting. After receiving BDS, she got business linkages to big shops. Business linkages helped her generate more income because she was able to sell to many people. Tone has now set up her own stall to sell the sardines in the tourist market, away from her tailoring business. When asked whether she had explored the possibility of selling her products to supermarkets or other shops in large quantities, she said that she was glad to be introduced to many buyers. SIDO asked her and advised her to improve the quality of her product so that she can sell more and be exposed to a bigger market.

The findings indicated that, all interviewees who used marketing services have evaluated the BDS providers as excellent. The findings reveal that, BDS facilitated women with establishment of trading relationship between rural and urban firms, small with large enterprises, collaborative marketing. The services have helped them to link with many customers, wholesalers, suppliers of their inputs at reasonable price. They were able to produce and sell quality products or render quality services, timely, meet the demand at a reasonable price and increase their income. Furthermore, BDS have contributed to the growth of women businesses and this is consistent with the aim of BDS, which states "One ultimate aim of most BDS is to help MSMEs become stable or grow so that they can improve the livelihoods of families, generate employment and contribute to economic growth".

Women further said that most of the services offered by BDS providers targeted SMEs available in the area. In recent years the demand from MSMEs has been increasing, make the suppliers of BDS serve them. Other services like seminars as well as workshops contribute a lot to women MSMEs. Unfortunately, a large percentage of women are not aware of BDS, and their importance to their businesses. As consistent to (URT, 2012; Rosenbusch et al., 2009), entrepreneurship training, business management training, and provision of market information were the three services regarded as very important. Although a few enterprises are aware of these services, there is a considerable gap between awareness of availability of the services and knowledge of benefits arising from service providers. The same services have been received and rated by small business owners as good. Almost one in three micro enterprise owners stated that they did not know the provider of services, nor did one in five small enterprise owners (URT, 2012; Rosenbusch et al., 2009). For micro enterprise owners, the cost of the service was also an obstacle. As a result, some who are aware of the importance believe that BDS have a negative impact on their businesses (goal conflict) and that will reduce their income if they accept the services.

All MSMEs received advisory, business development and marketing services so as to understand the business environment, the challenges and opportunities available in the global market. Only those in the tailoring and beauty sector received technical and trade fair services. It was not easy for those in the beauty sector to get socialized services as there are no experts in the area and the available services are too general. All MSMEs acknowledged the impact of BDS to their businesses.

\subsection{The Growth Levels for Women Owned MSMEs Arising from Use of BDS}

The information given by the owner managers and directors of companies briefly, explains the impact of BDS on their businesses. In addition, it highlights the importance of these services in terms of growth levels (growth indicators). Business growth can be measured by a number of direct and indirect indicators which are in the form of qualitative and quantitative growth. There are a number of direct business growth indicators such as increase in net income, number of employees and quantities of inputs purchased, and products and services sold. Indirect business growth indicators relate to the alleviation of the constraints that limit growth in businesses of women micro and small entrepreneurs. There are two types of growth indicators; quantitative and qualitative. These indicators are such as increased access to formal sector services or access to information and extension services, are likely to capture a number of constraints that women micro entrepreneurs face in many developing countries. Quantitative growth indicators are direct indicators widely used to measure growth of income, employment or assets specializing in one business. The number of variables such as increase in the value of assets, profitability, number of employees, quality of employment and market coverage are looked at, as follows: 


\subsubsection{Value of Assets}

The value of both fixed and current assets at the start of the food processing business amounted to 5 million Tshs, while at the end of 2014 was above 30million Tshs. In the case of textile and beauty sectors the value of sales at the start was 1.5 million, while at the end of 2014 was about 50 million. Faraja further stated that, since she produces drinking water she, needed a heavy-duty machine. Because she was unable to buy such a machine at the start, she just bought a simple one. After getting a loan with favourable terms from one of the friends, she bought a machine that cost 35 million. Therefore the value of Faraja's assets is now 70 million Tshs. It is clearly shown that the increase in value of assets has an impact on the level of sales, leading to an increase in business as a general concept.

\subsubsection{Number of Employees}

The results revealed that the average number of workers has increased from three employees when the business started to five in the food processing sector. In the beauty and health sector, the average number of employees has increased from 1 to 5 . In the textile sector the number has increased to six, which is contrary to Teddy's experience because the business comprises 17 women now. This means BDS have contributed to women's enterprises, which have led to an increased number of jobs. Some of the employees were on permanent terms, while other women entrepreneurs used their close relatives as part-time workers in their own businesses.

\subsubsection{Market Coverage}

Increased access to markets is also considered an aspect of growth level. The literature shows that most MSMEs sell to their immediate locality. The results of this study show that the proportion of enterprises selling to markets outside their districts has increased by a reasonable percentage, though most of them are selling in the region. However, one of their future plans as they said is to produce for both local and international market.

\section{Conclusions}

Entrepreneurship and business management training, advisory services and market information were the three services regarded as very important. BDS have contributed significantly to the business of women MSMEs. The impact of BDS is vivid as explained on the growth levels. However, some of the services are too general to be used for specific sectors which have brought some challenges to women MSMEs. Furthermore, there is a considerable gap between awareness of the service and knowledge on the impact arising from BDS and how to use such services. Compared to the awareness level and impact arising from BDS to their businesses, few small businesses which had received such services rated them as good. This conclusion seems to demonstrate that, not knowing who provides services and the benefits/impact of such services is the biggest obstacle to actually using them.

The study has come up with recommendations toward successful provision of BDS to WOEs. The support available to MSMEs is designed for the needs of micro and small enterprises but women owned businesses have been shown to have experienced difficulties, as the BDS providers do not distinguish between men and women in making use of the services. The paper calls for BDS providers to focus on demand driven in a holistic and participatory way than having a predetermined standard services as is the case in traditional/ supply driven approach. There is a need for government, BDS providers and other stakeholders to create awareness to MSMEs for the availability and use of BDSs. Government and donor community should advocate for business environment reforms that lowers the barriers to BDS providers for them to operate in a conducive and affordable way.

\section{Limitation and Contribution}

The study has limited its scope to impact of BDS to WOEs in MSMEs sector hence the results are influenced by the nature of activities, type of business and industry type WOEs are working in. However, it is the Authors belief that, developing countries of similar economic, social and cultural set up could benefit as well as these are among insights that contribute to economic growth and alleviate poverty of which women owned enterprises belong.

This paper was previously presented during the $17^{\text {th }}$ conference organized by International Conference for African Entrepreneurship and Small Business (ICAESB) on $11^{\text {th }}-12^{\text {th }}$ August, 2016 at University of Dar es salaam Business School, Tanzania.

\section{References}

Arlward, E. (2009). Traditional and Non-Traditional Female Entrepreneurs: An Exploration into what Influences their Selection of Industry Sector. Master's degree in Business Studies, Waterford Institute of Technology.

Creswell, J.W. (2009). Research Design: Qualitative, Quantitative, and Mixed Methods Approaches. London., SAGE Publications, Inc. 
Dainty, A., Green, S., \& Bagihole, B. (Eds.) (2007). People and culture in construction: contexts and challenges. London: Taylor \& Francis.

Denzin, N.K., \& Lincoln, Y.S. (1994). Handbook of Qualitative Research. London, Sage Publishers.

Ericson, M., \& Luther-Rune, C. (2012). Out of the ordinary? A study of prosperous women entrepreneurship in Tanzania. Master's thesis; Division of Business Administration, Department of Management and Engineering.

Fakhri, K.P., Ghanimat, P., Koopahi, M., \& Behnie, S. (2012). The study of the Effects of Personality and Psychological Traits Approach on the Rate of Entrepreneurship. Journal of Basic and Applied Scientific Research, 2(4), 4159-4166.

Global Entrepreneurship Monitor (GEM). (2012). Global Entrepreneurship Report.

Gupta, V.K., Turban, D.B., Wasti, S.A., \& Sikdar, A. (2012). Entrepreneurship and Stereotypes: Are Entrepreneurs from Mars or from Venus?, Best Paper, Academy of Management Conference, USA.

Hakala, T. (2008). Barriers to women in the non-traditional industries. Published, USA.

Hanson, S. (2009). Gender and entrepreneurial networks. Journal of Regional Studies, 43, $135-149$. https://doi.org/10.1080/00343400802251452

ILO. (2007). Entrepreneurship in Economic Development. International Labour Organization.

Kapp, J.M., \& Hunter, S.A. (2008). Women Entrepreneurs Across Racial Lines: Issues of Human Capital, Financial Capital and Network Structures. Edward Elgar Publishing, Cheltenham, UK and Lyme, US.

Lincolin, W.P. (2010). Impact of Gender on Economic Development. Paper presented at the Women's development Conference \& consultative annual meeting Addis Ababa, Ethiopia, 23rd - 25th of March, 2010.

Lingsey, N. (2012). Entrepreneurship in an Organizational Context; Recategorizing entrepreneurs: The Influence of Gender Categorization on firm Level Entrepreneurship. Copenhagen Business School, Department of Strategic Management and Globalization, $\mathrm{PhD}$ Thesis in Economics and Management, Denmark.

Nchimbi, M., \& Chijoriga, M. (2009). African Entrepreneurship. Business Management Journal, 2, $237-256$.

Nchimbi, M.I. (2003). Gender and entrepreneurship in Tanzania: A comparative Analysis of male-female's start-up motivation, individual characteristics and perceptions of business success.

Neumann, W. (2006). Social Research Methods: Qualitative and Quantitative Approaches. Pearson Education Publishers.

OECD. (2004). Women's entrepreneurship: Issues and policies. Paper presented at the Second OECD conference of ministers responsible for small and medium-sized enterprises. Istanbul.

Olomi, D.R. (2009). The context and process of African entrepreneurship and small business development. Dar es salaam, Tanzania, Otme publishers.

Rosa, P. (2013.). The Rationale for Developing Modern Entrepreneurship and Management Skills for Starting and Growing Entrepreneurs. The Concept of the Entrepreneurial Career Lader.

Rosenbusch, N., Rauch, A., Parker, S.C., \& Unger, J.M., (2009). Human Capital, Gender and Entrepreneurial Success: Empirical Evidence from China And Germany. Journal of Business Management, 34(4), $37-58$.

Rutashobya, L.K. (2000). Female Entrepreneurship in Tanzania and Strategic considerations. Business Management Review, 7(1).

Rutashobya, L.K., \& Olomi, D.R. (1999). African Entrepreneurship and Small Business Development. Dar es Salaam, Tanzania: Dar es Salaam University Press Ltd.

Sospeter, G.N. (2016). Challenges facing Women entrepreneurs in the Construction Industry: the case of Tanzania. Journal of Business and Economics, 7(11), 1907-1918.

Sospeter, G.N. (2017). Necessity versus Opportunity based entrepreneurship in Tanzania: The influence of Economic policies. Paper presented and published in the IAABD proceedings during the $18^{\text {th }}$ conference organized by International Academy of African Business and Development (IAABD) on $17^{\text {th }}-120^{\text {th }}$ May, 2017 at GeorgiaAtlanta, United State of America.

Sospeter, G.N., Nchimbi, I.N., Rwelamila, P.D., \& Masoud, I.M (2014). Reviewing Literature on Women Entrepreneurship in the Tanzanian Construction Industry: Establishing the missing Link. Journal of 
Construction in Developing Countries, 19(2), 93-103.

Stake, R.E. (2006). Multiple Case Study Analysis. London: The Guilford Press.

UDEC-ILO. (2002). Jobs, Gender and Small Enterprises in Africa: Women Entrepreneurs in Tanzania. A Preliminary Report. (ILO, IFP/SEED-WEDGE, October, 2002).

United Republic of Tanzania (URT). (2012). Economic Survey, Government Report, 2012.

Wangle, M.A. (2009). Perceptions of traits of women in construction. Unpublished Masters of science in Building construction, dissertation at the University of Florida, USA, 2009.

Yin, K.R. (1994). Case Study research design and methods. Oaks, CA: Sage Publications. Inc.

Yin, K.R. (2009). Case Study Research: Design and Methods (4 ${ }^{\text {th }}$ ed.). (Applied social research methods v.5). Thousand Oaks, CA: Sage Publications, Inc. 